\title{
Reseña del libro de Mariana Maggio, Invención, inmersión y alteración. Tres claves para pensar la didáctica en la clase universitaria'
}

\author{
Sandra Della Giustina
}

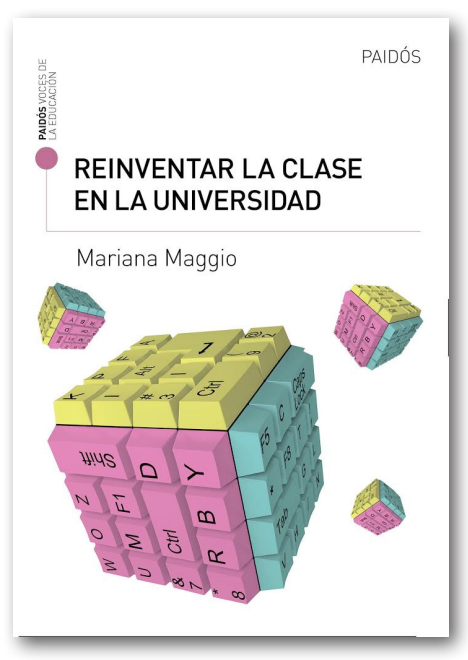

$\mathrm{L}$

a incorporación y uso de las tecnologías de la información y la comunicación (TIC) en el plano educativo ha generado en estos últimos años gran cantidad de publicaciones, que dan cuenta de experiencias, aplicaciones y propuestas pedagógicas, en las que con frecuencia aparece de manera ciertamente esperanzadora la noción de innovación. Como si una serie de mediaciones tecnológicas o la incorporación de nuevos dispositivos a la clase pudieran resolver per se problemáticas educativas de toda índole, incluso en las aulas universitarias.

El nuevo libro de Mariana Maggio propone una alternativa a las didácticas tradicionales. Afirma que la clase universitaria, aquí abordada como objeto de análisis, se enfrenta por primera vez en la historia a condiciones que la están vaciando del sentido que tuvo hasta hace algunas décadas. "Y pocas cosas podrían resultar más extrañas para un docente" (p. 18). Esta apreciación tan contundente sobre la didáctica clásica, logra la tensión necesaria para que los lectores - que seguramente supone que son docentes - intenten pensar y re-pensar sus propias prácticas de enseñanza universitaria.

\section{Sandra Della Giustina}

sandydg@gmail.com

Argentina. Licenciada en Educación y doctoranda en Ciencias Sociales y Humanidades, Universidad de Quilmes, Argentina, Especialista en Educación, Medios y TIC, FLACSO-Argentina. Docente de la Cátedra Didáctica General y Teoría Educativa del área Ciencias de la Educación del Departamento de Humanidades, Universidad Nacional del Sur, Argentina. Temas de investigación: Trayectorias educativas y TIC en educación superior.

\footnotetext{
${ }^{1}$ Mariana Maggio (2018), Reinventar la clase en la Universidad, Buenos aires, CABA, Paidós.
} 
Esta obra - que forma parte de la colección Voces en Educación de Editorial Paidos - está estructurada en siete capítulos, a lo largo de los cuales la autora despliega su propuesta en una estructura más cercana a los géneros de ficción - a los que referirá promediando el libro- que al estilo de los libros de pedagogía. Maggio da cuenta del estado del arte como si se tratara de la síntesis argumental de un clásico del cine.

\footnotetext{
"En esta sociedad red (Castells, 1999) en la que nos toca vivir y educar, las formas en que se produce el conocimiento cambiaron y lo van a seguir haciendo de la mano de las tecnologías digitales[...] los estudiantes también cambiaron y lo constatamos cada vez que los vemos mirar fijamente sus teléfonos celulares, fingimos que no lo notamos y seguimos adelante con la clase" (p. 19).
}

A partir de esta afirmación la autora plantea varios interrogantes que intenta responder en los capítulos siguientes: sobre la forma en que se enseña en la universidad; si es posible o no mantener en el tiempo estos formatos tradicionales de enseñanza y sobre la insistencia de enseñar conocimiento acumulado "si sabemos que lo más importante es el conocimiento que seremos capaces de construir" (p. 20).

Mariana Maggio invita a replantear las prácticas de enseñanza, con el argumento de sus propios trayectos de formación y de su experiencia como docente en la cátedra Fundamentos de Tecnología Educativa de la Universidad de Buenos Aires (UBA), las discusiones conceptuales con el equipo de investigación del proyecto UBACyT "Prácticas de la enseñanza re-diseñadas en el escenarios de alta disposición tecnológica"; refiriendo a sus publicaciones anteriores y a su maestra y antecesora como titular de la cátedra Edith Litwin.

En el capítulo 1 titulado La Era de la invención, la autora dedica la primera parte a alertar sobre el sentido actual de una de las estrategias más frecuentes en las clases universitarias: las explicaciones que, acompañadas casi siempre de la aplicación y la verificación como práctica hegemónica, "ya desde hace tiempo están disponibles a toda hora y en todo lugar en cualquier dispositivo tecnológico" (p. 23). Propone revisar ese apego epistemológico a las explicaciones para detectar en cada campo cuáles son las que vale la pena mantener y cuáles no. Pero se atreve a más, cuando afirma que las tendencias actuales plantean "enlatar" las explicaciones a fin de difundir el conocimiento en formato de videos, audios, podcast o presentaciones multimedia transmitidas por canales diversos. A renglón seguido Maggio tranquiliza aclarando que lo que parece haber cambiado de manera irreversible es que la explicación de lo acabado, tema por tema, ya no necesita el marco de la clase para existir.

Pero la tranquilidad dura poco, dado que en las páginas siguientes la autora de Enriquecer la enseñanza (2012), da cuenta de una "amenaza de bomba en el corazón de la didáctica clásica". Remite así a una expresión que ella misma califica como "no feliz" pero que sirve a los fines de la trama del relato, esta amenaza de bomba le permite, entonces, graficar la inminente pérdida de sentido de la práctica de enseñanza sustentada en la explicación, la repetición y el abordaje de contenidos fragmentarios y finitos.

En el apartado "Inventar la clase", dentro del mismo capítulo 1, Maggio recurre a su experiencia docente junto a Edith Litwin, para recuperar el que tal vez sea el rasgo más distintivo de su maestra y mentora: el metaanálisis de la clase y la que denominó "secuencia de progresión lineal con descentraciones múltiples por invención".

Otro de los puntos clave de la obra de Maggio es su propuesta de re-invención de la clase universitaria a partir de la idea de pensarla desde la investigación científica "no para relatar nuestras experiencias pasadas sino para vivirlas junto a nuestros estudiantes” (p. 29).

Frente al entusiasmo generalizado de mejorar el sistema educativo a partir de más evaluación 
tradicional y estándares, Maggio se esperanza con la posibilidad de generar una "didáctica en vivo", apelando a la inventiva para pensar la clase como trama original que dé lugar a la construcción de conocimiento didáctico también original.

En el capítulo 2, Tiempos inmersivos, analiza las clases universitarias a la luz de los fenómenos de la cultura popular, aquellos que en algún momento fueron la radio o la televisión y hoy se asocian a las series de TV e internet. Ante esos nuevos formatos narrativos, la autora recupera la noción de inmersión de Rose (2011) quien define a la tecnología, y en especial a internet, como un camaleón que puede actuar como todos los medios a la vez y que está cambiando los modos de narrar, "ya no sólo somos espectadores sino que podemos habitar las historias". A partir de esta idea, Maggio vuelve como en un flashback al capítulo anterior de este libro, para marcar una analogía entre las explicaciones hegemónicas de la clase universitaria con las viejas series de televisión, alejadas de la impronta de las nuevas formas de narrar. Y alerta que los nuevos formatos están poniendo en jaque otro pilar de la didáctica clásica, aquel que Litwin (1997) identificó como secuencia progresiva lineal.

Las condiciones que sostienen una clase distinta es el título del capítulo 3 en el que Maggio plantea la necesidad de un rediseño de las prácticas de enseñanza, si bien reconoce los condicionamientos institucionales, afirma que es posible pensar en un cambio positivo a partir de las tensiones del entorno, en muchos casos "más asociadas a lo que podríamos llamar usos y costumbres que a limitaciones de orden estructural" (p. 70).

En el mismo capítulo, en el apartado "Interpretaciones curriculares", la autora propone revisar holísticamente el programa, la forma en que se articulan los temas y se establecen los contenidos mínimos hasta la forma en que los docentes están acostumbrados a abordarlo. Refiere y se incluye en el habitus de mirar el curriculum como si se tratara de un recetario. Y en contraposición propone orientaciones para la selección de temas, la incorporación de lo que denomina objetos contemporáneos como videos, videojuegos, entre otros, con la intención de escapar a la lógica acumulativa de los contenidos fragmentados y descontextualizados, que se traduce en términos de los estudiantes en cierta lógica expulsiva ya que "los deja afuera del sistema porque no encuentran sentido al estudio de cuerpos demasiado extensos" (p. 74).

$\mathrm{Si}$ bien la autora reconoce las limitaciones en cuanto a los protocolos institucionales, propone organizar las unidades temáticas en torno de preguntas complejas: "El tratamiento que demos a los contenidos en clase no puede omitir la fuerza de la pregunta que los anticipa en el programa y con eso, ya crea una escena rica para la alteración de la secuencia progresiva lineal" (p. 78).

En el mismo capítulo Maggio analiza los componentes de la evaluación que es necesario "alterar", así como la forma en que los marcos teóricos deben pasar de ser objetos de reproducción para resaltar las voces de los autores: "Elegir cinco o seis libros es una decisión difícil que no impide que traigamos otros autores y voces de diversos modos que van desde hacer pequeñas lecturas en clase hasta invitar a los autores a participar, en forma presencial o remota" (p. 81). Y convoca luego a explicitar las lógicas con las que se plantean las clases.

En el capítulo 4 la autora invita a pensar Otra evaluación, Maggio alerta sobre la persistencia de la instancia de verificación como sinónimo de evaluación. Y sostiene que "la evaluación tiene que dejar de ser una instancia de verificación de que lo que enseñamos parece haber sido aprendido para convertirse en una propuesta que genere consideraciones para mejorar nuestras prácticas” (p. 93). Para lograrlo plantea la noción de "evaluación en perspectiva" a partir del análisis crítico del caso o problema y dos elementos claves: la puesta en juego de los elementos teóricos del campo como cuestión central y la reconstrucción del parcial como objeto. Una especie de metaevaluación. 
Una didáctica en vivo es el título del capítulo 5, que se inscribe en un espíritu de época y que Maggio explica como una didáctica que registra los atravesamientos de las tecnologías en la subjetividad y la cultura y los abraza en sus construcciones. Esta noción de didáctica en vivo, está anclada en dos categorías teóricas que la autora ha desarrollado en profundidad en otra de sus obras: la enseñanza poderosa y la inclusión genuina. En el caso de la enseñanza poderosa, explica: "encarna esas prácticas de la enseñanza que dejan huella y que todos los docentes quisiéramos poner en juego al menos de vez en cuando" (p. 118). Y respecto a la inclusión genuina afirma: "de algún modo expresa varios rasgos de la enseñanza poderosa al dar cuenta de propuestas que se construyen en tiempo presente porque se reconocen tanto los cambios epistemológicos en el plano de las disciplinas como las transformaciones sociales y culturales" (p. 133). Es este capítulo el que conjuga las nociones de invención, inmersión y alteración que abordó en los anteriores.

Los últimos dos capítulos, La clase como experiencias que vale la pena vivir y La enseñanza como proyecto colectivo, plantean la necesidad de repensar la universidad desde una perspectiva inclusiva, con énfasis en prácticas de enseñanza que aseguren el acceso, permanencia y

\section{Referencias}

Litwin, E. (1997), Las configuraciones didácticas. Una nueva agenda para la enseñanza superior, Buenos Aires, Paidós.

Maggio, M. (2012), Enriquecer la enseñanza: los ambientes con alta disposición tecnológica como oportunidad, Madrid, Grupo Planeta. egreso de todos los estudiantes. En el último capítulo Maggio pone el acento en la construcción subjetiva grupal, la importancia de la inteligencia colectiva como marca de época y la necesidad de generar un verdadero movimiento colectivo capaz de romper con las propuestas hegemónicas para alterar las prácticas de enseñanza: "Tal vez haya llegado la hora de construir un movimiento que resista la inercia instalada en las instituciones y defina nuevas reglas" (p. 172).

Luego de experimentar la lectura de esta obra, aparecen nuevas preguntas: ¿cómo pensar colectivamente cambios en las prácticas de enseñanza en la universidad y a su vez mantener el espíritu autónomo de cada cátedra en la forma de valorar la innovación?, ¿es posible pensar el cambio que propone la autora en las clases universitarias de gran matrícula, ambientes que no siempre cuentan con alta disponibilidad tecnológica? Éstos son algunos de los interrogantes con los que cerramos el libro. Y después de haber disfrutado de su lectura, nos vuelve la esperanza de que el cambio que tantas veces deseamos en nuestras clases puede ser posible. Mariana Maggio logra en esta obra recuperar el espíritu de la didáctica, como disciplina en permanente evolución, capaz de reconfigurarse en prácticas de enseñanza innovadoras.
Rose, F. (2011), The art of immersion: how the digital generation is remaking. Hollywood, Madison Avenue, and the way we tell stories, Nueva York, W.W. Norton Company.

Cómo citar este artículo:

Della Giustina, Sandra (2019), “Reseña del libro de Mariana Maggio, Invención, inmersión y alteración. Tres claves para pensar la didáctica en la clase universitaria", en Revista Iberoamericana de Educación Superior (RIES), México, UNAM-IISUE/Universia, vol. X, Núm. 27, pp. 231-234, DOI: dx.doi.org/10.22201/iisue.20072872e.2019.27.348 [consulta: fecha de última consulta]. 